\title{
Thermal-Mechanical Analysis for in-Vessel Diagnostic Components in W7-X
}

\author{
M.Y.Ye, A. Werner, M. Hirsch, A. Weller, H. Thomsen and R. König \\ Max-Planck-Institut fuer Plasmaphyisk, EURATOM Association, Wendelsteinstr. 1, 17491 Greifswald, Germany
}

\begin{abstract}
For long pulse plasma operation of the W7-X stellarator, the most serious challenge for the design of in-vessel diagnostic systems is the thermo-mechanical problem. Thermal load from convective losses and from plasma radiation can be as high as $500 \mathrm{~kW} / \mathrm{m}^{2}$ at some locations close to plasma. The typical thermal load from plasma radiation alone ranges from several 10 to $100 \mathrm{~kW} / \mathrm{m}^{2}$ as derived from 3-D Monte-Carlo simulations. A finite element analysis (FEAANSYS) is conducted for a better understanding of thermo-mechanical effects on in-vessel diagnostic components and to guide the design of the diagnostic system for steady state operation. All in-vessel diagnostic components require active cooling. Besides for long-pulse plasma operation optical components must be optimized to minimize thermal deformations. In this paper, we present the thermo-mechanical analyses of the $\mathrm{CO}_{2}$-laser interferometer retro-reflectors, the diamagnetic loops and the soft X-ray multi camera tomography system (XMCTS).
\end{abstract}

Keywords: W7-X, steady state diagnostics, heat load, thermal-mechanical analysis

PACS: 52.55.Hc, 52.70.-m

\section{INTRODUCTION}

The superconducting stellarator W7-X being under construction in Greifswald is designed for stationary operation (30 minutes) with cw heating by up to about $10 \mathrm{MW}$ ECRH, and additional heating up to $14 \mathrm{MW}$ for $10 \mathrm{~s}$ by NBI and ICRH. The actively water cooled divertor target plates have been designed to withstand heat loads of up to $10 \mathrm{MW} / \mathrm{m}^{2}$ and the baffle plates have been designed to withstand up to $1 \mathrm{MW} / \mathrm{m}^{2}$ [1]. Most of the in-vessel area is covered by water cooled panels which are able to remove a power load of $130 \mathrm{~kW} / \mathrm{m}^{2}$ in steady state operation. It is a particular challenge to design the in-vessel diagnostic components in such a way as to make them steady state compatible by proper shielding and active cooling. In some cases a specially designed actively cooled heat shield is required to protect in-vessel diagnostic systems from high, mainly convective thermal loads of up to $500 \mathrm{~kW} / \mathrm{m}^{2}$. Diagnostic components located behind such a heat shield often need further individual cooling due to the significant thermal emission of the cooled but still rather hot heat shield at full thermal load. In other cases the direct exposure of diagnostic components like windows, mirrors and detectors to radiative thermal loads of up to $100 \mathrm{~kW} / \mathrm{m}^{2} \mathrm{can}$ not be avoided [2]. For optical components the thermal deformation must be taken into account and should be minimized according the requirements [3]. This thermo-mechanical analysis is a key element in the design of diagnostic systems for steady state operation.

\section{ACTIVELY WATER COOLED HEAT SHIELD}

A water cooled heat shield has been designed to protect in-vessel diagnostic systems from high thermal loads of up to $500 \mathrm{~kW} / \mathrm{m}^{2}$. The typical heat shield elements consist of graphite tiles (on the plasma facing side) clamped onto copper-chromium-zirconium (CuCrZr) heat sink structures with brazed stainless steel (SS) cooling tubes as shown in Fig.1. The interlayer of 1mm Papyex graphite foil between tiles and heat sink is used to improve the thermal contact. A heat transfer coefficient of $2 \mathrm{~kW} / \mathrm{m}^{2} \mathrm{~K}$ at this interface is obtained [1]. The thermal analysis of the heat shield was carried out assuming a heat load of $500 \mathrm{~kW} / \mathrm{m}^{2}$ on the graphite surface for 30 minutes to investigate the temperature evolution of the components. The temperature must remain under an acceptable value with respect to critical material properties. The active cooling is modelled as a fixed temperature of $40^{\circ} \mathrm{C}$ on the inner surfaces of the cooling tubes. Radiation cooling is included in the model. 
The calculated results indicate a maximum temperature of $830^{\circ} \mathrm{C}$ on the graphite surfaces, and of $430^{\circ} \mathrm{C}$ on $\mathrm{CuCrZr}$ (below maximum allowable temperature of $475^{\circ} \mathrm{C}$ ) shown in Fig.1. The calculated results indicate that the designed heat shield is able to withstand heat loads of up to $500 \mathrm{~kW} / \mathrm{m}^{2}$.

For some diagnostics the heat shield does not fully cover to all diagnostic parts due to the required measurement technique. Some components (e.g. retro-reflectors, detectors and windows) need to be directly open to the plasma or at least have an observation slit. These components will typically suffer from thermal loads of $10-100 \mathrm{~kW} / \mathrm{m}^{2}$ by plasma radiation [2]. It should be noted that all diagnostic parts located behind the heat shield still receive radiation from the hot rear side surfaces of the heat sink (surface temperatures of $\sim 400^{\circ} \mathrm{C}$ as shown in Fig. 1 result in thermal loads of about $6 \mathrm{~kW} / \mathrm{m}^{2}$ ). Therefore, based on the requirements of different diagnostics and spatial restrictions a detailed thermal analysis of the entire system is necessary to find a way to keep the temperature of diagnostic components from rising to an unacceptable value.

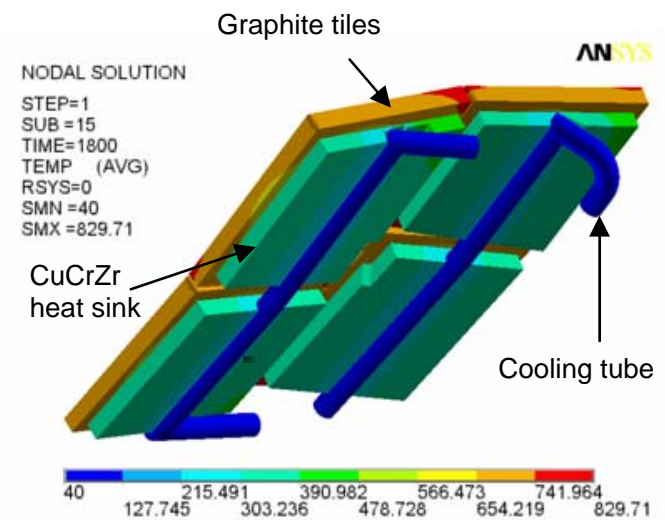

(a)

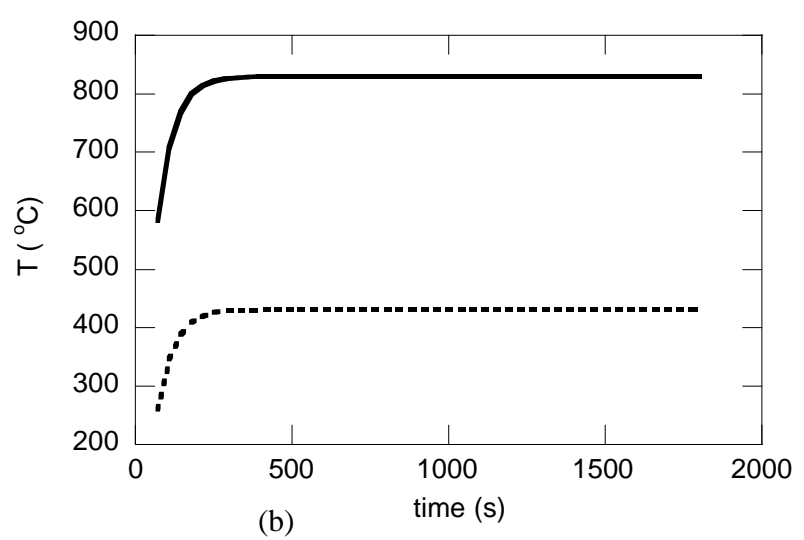

(b)

FIGURE 1. (a) FEA calculated temperature $\left({ }^{\circ} \mathrm{C}\right)$ of the water cooled heat shield with $500 \mathrm{~kW} / \mathrm{m}^{2}$ for 30 minutes. (b) The temperature evolution at the position of the maximum temperature of the graphite tile (solid line) and heat sink (dotted line).

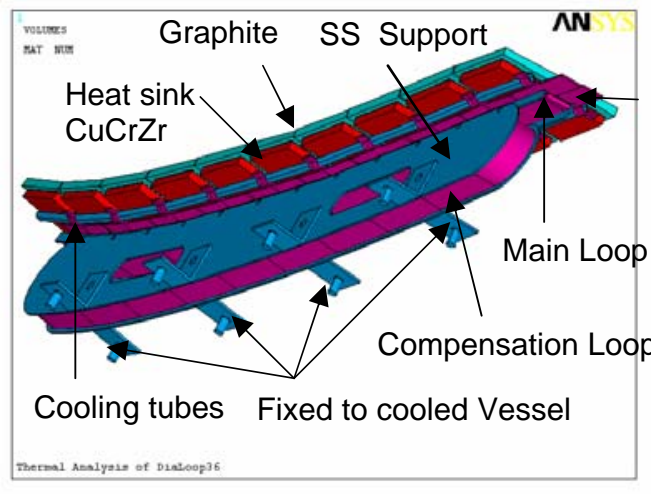

(a)

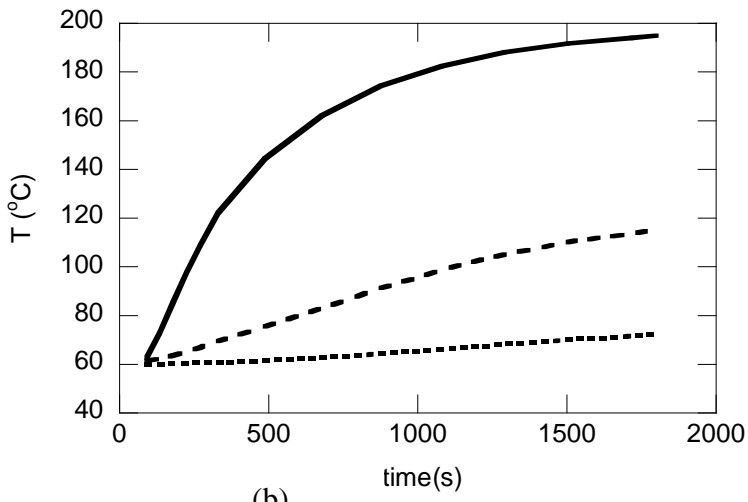

(b)

FIGURE 2. (a) Components of the diamagnetic loop and heat shield. (b) Temperature evolution at the position of maximum temperature of the radiation shield (solid line), of the main loop (dashed line) and of the compensation loop (dotted line).

\section{DIAMAGNETIC LOOPS}

Diamagnetic loops are used for the measurement of plasma energy in a fusion device. These loops are made of Kapton insulated ribbon cable and are positioned between the plasma vessel and the water cooled heat shield, which provides a complete shielding of direct thermal load from the plasma. The main loop is positioned very close to the heat sinks, the compensation loops are positioned below the main loop. All loops are supported from both sides by SS plates (Fig. 2(a)), which are fixed by bolts to the water cooled vessel (not shown). First thermal FE analyses revealed that the direct radiative heat transfer onto the main loop from the hot heat sinks results in temperatures of 
the main loop in excess of $250{ }^{\circ} \mathrm{C}$. In order to suppress the radiative load onto the main loop a radiation shield (SS) mounted on cooling tubes is positioned between the heat sinks and the main loop as shown in Fig. 2(a). A thermal analysis of the entire system was carried out with $500 \mathrm{~kW} / \mathrm{m}^{2}$ onto the graphite surface for 30 minutes, and the active cooling is considered as a fixed temperature of $60^{\circ} \mathrm{C}$ on the inner surfaces of the cooling tubes and on outside surface of the vessel. A heat transfer coefficient of $2 \mathrm{~kW} / \mathrm{m}^{2} \mathrm{~K}$ between the cooling tube and the radiation shield is assumed. The heat exchange between the loops and the radiation shield as well as support parts is only by radiation. The emissivity of all materials is assumed to have a value of 0.5 except for graphite for which an emissivity of 0.8 has been used. The maximum temperature is reached after 30 minutes and amounts to $116{ }^{\circ} \mathrm{C}$ on the main loop, 72 ${ }^{\circ} \mathrm{C}$ on the compensation loop and $195^{\circ} \mathrm{C}$ on the radiation shield (Fig. 2b). The analysis results predict an effective radiation shielding by the stainless steel radiation baffles.

\section{SOFT X-RAY MULTI CAMERA TOMOGRAPHY SYSTEM (XMCTS)}

The XMCTS has been proposed for W7-X for the tomographic reconstruction of equilibrium flux surfaces and MHD mode structures [4]. The system consists of 20 pinhole cameras, each with a photo diode array (22 Si-detector channels), entrance slit (SS), Be-foil holder (Cu) and detector holder (SS) as shown in Fig. 3a. The system is located behind the water cooled heat shield with a hole for the camera view (Fig. 3b). Although the water cooled heat shield protects the camera body from high thermal load from plasma, the camera body still receives radiation from the hot heat shield and plasma radiation through the observation pinhole in the shield. Since the Si-detectors require a working temperature below $30^{\circ} \mathrm{C}$ the cameras need active cooling, which is realised with active cooled side plates (CuCrZr) from both sides. A detailed thermal analysis of the entire system was carried out with $500 \mathrm{~kW} / \mathrm{m}^{2}$ on the graphite surface for 30 minutes. The plasma radiation of $100 \mathrm{~kW} / \mathrm{m}^{2}$ is equivalent to black body radiating surface of $880^{\circ} \mathrm{C}\left(\mathrm{q}=\sigma \mathrm{T}^{4}\right)$ in front of the opening hole in the heat shield. The active cooling is considered as a fixed temperature of $20^{\circ} \mathrm{C}$ on the inner surfaces of the cooling tubes.

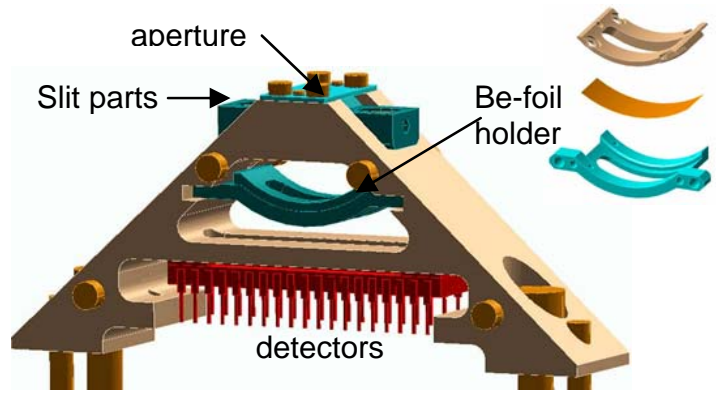

(a)

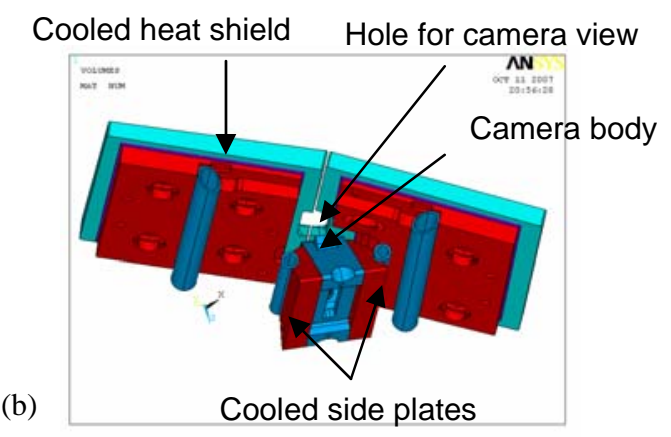

FIGURE 3. (a) The design of camera. (b) The independent cooled camera body positioned behind cooled heat shield.

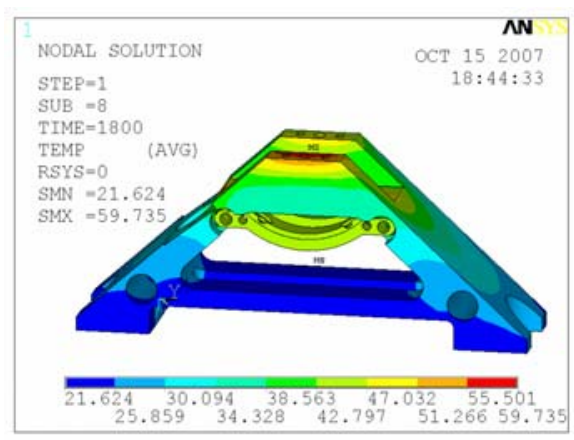

(a)

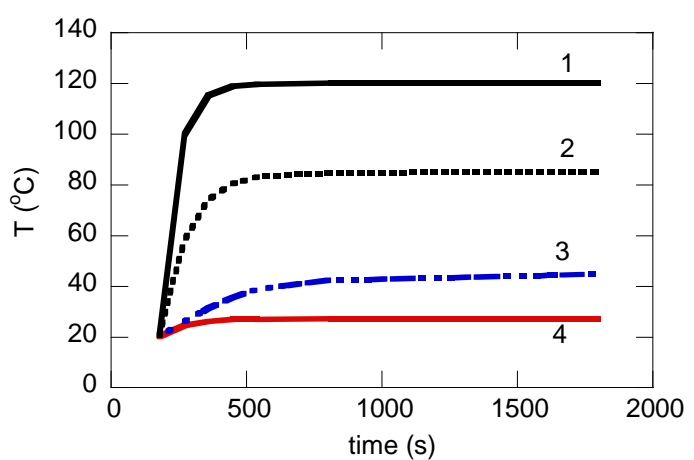

(b)

FIGURE 4. (a) The temperature distribution of camera and Be-foil holder in ${ }^{\circ} \mathrm{C}$. (b) The temperature evolution at the position of the maximum temperature of the aperture (1), of the slit parts (2), of Be-foil support (3) and of the detectors area (4). 
The heat exchange between the main components by radiation is considered in the calculations. Figure 4 shows the calculated temperature distribution on the camera body components. The maximum temperatures reached after 30 minutes are $27^{\circ} \mathrm{C}$ in the detector area, $45^{\circ} \mathrm{C}$ on the Be-foil support, $85^{\circ} \mathrm{C}$ on the slit part, and $120^{\circ} \mathrm{C}$ at the aperture. The analysis results show that the temperature in the detector area is less than $30^{\circ} \mathrm{C}$ if cooling of each side of the camera body at $20^{\circ} \mathrm{C}$ is provided.

\section{CORNER-CUBE-RETRO REFLECTORS (CCR)}

Due to the necessarily strongly shaped modular coils in W7-X and the divertor structures [5, 6] large ports poloidally opposite to each other can not be realised. Therefore the multi-channel $\mathrm{CO}_{2}$-Laser interferometer must use Corner-Cube-Retro reflectors (CCR) which have to be integrated in the cooled heat shield. For steady state operation the main design challenge is to guarantee the optical specifications of these CCR with respect to surface flatness; in particular deformations must be well below $1 \mu \mathrm{m}$ over each of the three reflector surfaces. Optimum material properties with respect to heat conductivity and thermal expansion are obtained with molybdenum (Mo) or tungsten (W) as reflector material. However, strong deformations would result from the stiffness of the CCR arrangement with mutual angles of 90 degrees. It is proposed to minimise these mechanical stresses by a design with appropriate slits between reflectors to allow for thermal expansion. An illustration for a single CCR is given in Figure 5(a). Each of the three Mo-reflectors is supported by rather thick Mo-structures which are all together fastened in a CuCrZr housing that is finally integrated in the cooled heat shield. Stresses result mainly from the mutual 90 degree angles but also - to a minor contribution - from the different thermal expansion at the Mo - CuCrZr interface and the unavoidable temperature gradients across in the Mo-structures itself. To minimize the impact of stress resulting from the interface to the reflector surface the structure is kept sufficiently high. Figure 5(b) shows the temperature distribution calculated for one reflector at a heat load of $90 \mathrm{~kW} / \mathrm{m}^{2}$ on the mirror surface (top surface). For a bottom temperature of $270{ }^{\circ} \mathrm{C}$ which easily can be achieved by heat contact to the surrounding actively cooled wall elements the expected temperature on the mirror surface is rather uniform at $293^{\circ} \mathrm{C}$. For this temperature distribution the mirror deformation is calculated assuming that the bottom is mechanically fixed to the housing. Figure 5(c) shows that the relative deformation (perpendicular to the mirror surface) across the diagonal line from A to B is less than $0.3 \mu \mathrm{m}$. This value is close to what is expected for the unavoidable bending of a Mo-slab with different temperatures on top and bottom resulting from a given heat flux across the slab.

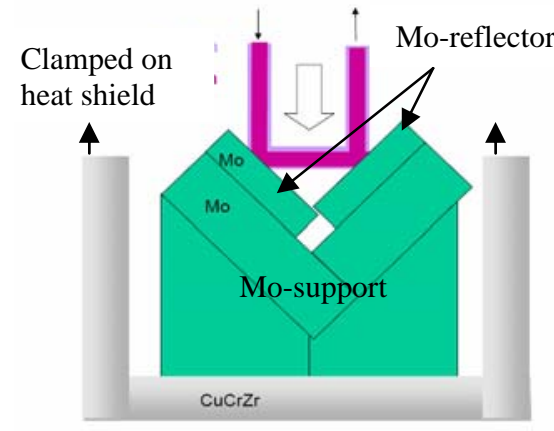

(a)

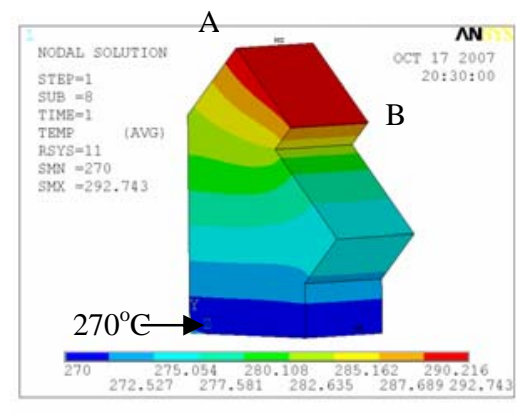

(b)

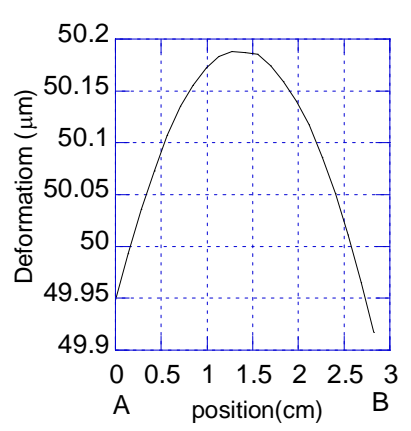

(c)

FIGURE 5. (a) Conceptual design of CCR. (b) The temperature distribution on reflector. (c) Deformation across surface.

\section{REFERENCES}

1. H. Greuner et al., Fusion Eng. Des. 66-68, 477-452(2003)

2. T. Eich, A. Werner, accepted for publication in Fusion Sci. \& Technol. (2007)

3. H-J Hartfus et al., Diagnostics for steady state plasmas, Plasma Phys. Control. Fusion 48, R83-R150 (2006)

4. H. Thomsen et al., this conference.

5. H. Dreier et al., this conference.

6. P. Kornejew et al., Rev. Sci. Instrum. 77, 10F128 (2006) 